\title{
NEM UTOPIA NEM DISTOPIA: PROPOSTAS PARA UM FUTURO BOM DE SER VIVIDO
}

\author{
Neither utopia nor dystopia: proposals for a good future to be lived
}

\author{
Marijane Vieira Lisboa
}

PUC-SP

\begin{abstract}
Resumo: Esse artigo examina a crítica de Hans Jonas à utopia marxista, questionando os limites ecológicos existentes para se atingir o ideal de uma sociedade de abundância e afirma que sua concepção de uma vida módica e respeitadora daqueles limites coincide com as tendências e propostas mais avançadas que surgiram nos úlitimos tempos como altemativas ao crescimento e ao desenvolvimento.
\end{abstract}

Palavras-Chave Utopia marxista - limites ecológicos - alternativas ao crescimento.

Abstract: This article examines Jonas's critique of the Marxist utopia, questioning the existing ecological limits to achieve a ideal of a society of abundance and affirms that his conception of a modest life and respecting these limits coincides with the most advanced proposals that have emerged in recent times as alternatives to growth and development.

Keyworks: Marxist utopia - ecological limits - altematives to growth.

No último capítulo do Princípio Responsabilidade, o Capítulo VI: A Crítica da Utopia e a Ética da Responsabilidadet, ao desenvolver a sua crítica ao utopismo marxista, Jonas se propõe a fazê-la em dois passos: primeiro, examinar as condições físicas da possibilidade dessa utopia e em segundo lugar, tratar dos aspectos subjetivos, ou seja, da sua desejabilidade.

Pretendo fazer algumas considerações sobre esse primeiro passo, ou seja, sobre o que podemos dizer hoje em dia a respeito dessa capacidade física do Planeta em sustentar uma utopia que suponha um aumento considerável dos meios materiais de vida e daí discutir até que ponto as conclusões de Jonas em 1984, viram-se contestadlas ou reiteradas pelo estado da arte da ciência ecológica atual e como se coloca hoje a questão da utopia e da distopia para aqueles enfrentam a questão da ecologia política.

Primeiro rememorarei a linha argumentativa de Jonas nessa primeira parte do capítulo. Para discutir o tema, Jonas recupera as condições de possibilidade da utopia marxista tal qual podem ser extraídas das definições marxistas do comunismo:

1. A condição do comunismo é a abundância material, de modo a satisfazer as necessidades de todos e em segundo, que seja fácil adquirir essa abundância.

2. Ambas, a abundância e a obtenção dessa abundância seriam alcançadas pela radicalização da técnica avançada, ou seja, daquilo que Bloch chamou de "reconstrução da natureza" e da mecanização e automação do trabalho. Como reconhece Jonas, esse processo de "libertação" da força do trabalho do trabalho já estaria em curso, e não

1 JONAS, Hans. O Princípio Responsabilidade: ensaio de uma ética para a civilização tecnológica, Rio de Janeiro, Contraponto/Editora PUCRio, 2006, p.289 e seguintes. 
precisaríamos pensar no comunismo para examinar a sua viabilidade. O avanço da ciência e da técnica são efetivamente constantes em todas as partes do mundo - e Jonas escrevia quando ainda existia o mundo socialista - e nada indicava que este avanço pudesse se deter em algum momento.

3. A vantagem de uma sociedade comunista sobre sociedades capitalistas não estaria então na ciência ou na técnica, mas na melhor seleção e condução social do progresso técnico e sobretudo em uma divisão mais igualitária dos seus frutos. Se isso ocorresse, diz Jonas, "essa distribuição mais igualitária dos frutos do progresso técnico poderia diminuir muitas das privações do planeta"2, "pois boa parte dos problemas não é de natureza técnico-material, mas sim de natureza econômico-política"s.

É nesse momento, então, que Jonas introduz a questão dos limites físicos: tais avanços da ciência considerados como plenamente possíveis, permitiriam, na melhor das hipóteses em um planeta inteiramente comunista, uma distribuição da riqueza muito modesta, tornando apenas tolerável a existência humana de milhões de pessoas hoje condenadas à mais negra miséria. Assim, para elevar essa qualidade de vida a níveis mais dignos, ainda que "pré-uttópicos" "a palavra de ordem teria que ser o crescimento da produção global e uma técnica mais intensa e mais agressiva e isso apenas para manter o status quo da população crescente no Planeta. "Para uma economia universal "de abundância com lazer", como prevê a utopia, seria necessária uma extraordinária elevação da potência de produção e técnica. Supondo que essa extraordinária elevação fosse possível, aí apareceria o problema dos limites da natureza, ou nos termos de Jonas "como a Natureza reagirá a essa agressão intensificada". Nesse caso, como diz Jonas, "não importa se essa agressão venha da direita ou da esquerda, que o agressor seja marxista ou burguês liberal, pois as leis da Natureza não são nenhum preconceito burguês (ainda que os ideólogos marxistas tendam a crê-lo, e Stalin assim o tenha entendido, como sabemos, no caso das leis da genética) ${ }^{\text {n"4. }}$.

Como Jonas afirma que "ninguém duvida de que haja tais limites, "a questão é saber se a utopia se situa dentro ou fora deles" (301). Jonas aindla chama a atenção para o fato de que muitas vezes só percebemos que ultrapassamos tais limites quando seus efeitos nocivos começam a afetar nossos ganhos e muitas vezes trata-se de uma ultrapassagem "sem volta atrás", afetando um sistema inteiro que era dotado de um equilíbrio múltiplo e delicado, provocando assim uma catástrofe humana. Estamos, pois, diante de uma questão neutra do ponto de vista ideológico e motivacional, de ordem quantitativa: "quais são esses "limites" e onde eles estão? A que distância nos encontramos dele?

"Aqui o filósofo nada tem a dizer, apenas a ouvir", pois a resposta a essas questões "situa-se no domínio do saber da jovem ciência ecológica e em particular, nas áreas de conhecimentos de biólogos, agrônomos, químicos, geólogos, climatologistas e outras ciências e conhecimentos ${ }^{6}$. Lamentavelmente, continua Jonas, "a ciência atual não é capaz de oferecer resulltados seguros. Todas as predições quantitativas nos diversos campos do saber são incertezas, para não falarmos da sua integração em um todo ecológico, na suposição de que elas possam ser passíveis de cálculo matemático."

Jonas, examina, no entanto, alguns casos em que há evidência de limites, de modo a poder avaliar a viabilidade dos projetos utópicos:

Aumento significativo da produção de alimentos: a seu ver, isso requereria aumento do uso de fertilizantes artificiais, que são uma forma de energia, e a adoção dessas tecnologias agrárias de maximização da produção poluiria recursos hídricos e áreas costeiras com seus efeitos nocivos transmitidos pela cadeia alimentar, traria a salinização dos solos pela irrigação, a erosão pela aragem de campos e a mudanças

\footnotetext{
2 Idem, p.300.

3 Ibidem, p.300.

4 Ibidem, p.300.

5 Ibidem, p.301.

6 Idem. p.301

7 Ibidem. p.301
} 
climáticas devido ao desmatamento, entre outros impactos negativos. Tudo isso se fosse mantida a população mundial estabilizada nos níveis da época ${ }^{8}$, o que de fato, aliás, não aconteceu.

Matérias-primas: É possível que haja matéria- prima suficiente no Planeta, dizia Jonas, mas a maior parte dela se encontra em camadas profundas, cuja extração exige quantidades colossais de energia. Por isso, diz Jonas, esse é o x do problema. "Seu nome é energia, e não matérias-primas"

O problema energético: Em primeiro lugar, Jonas divide as fontes energéticas em renováveis e não renováveis, para então analisar a sua disponibilíidade:

1) os combustíveis fósseis: o grande consumo atual, que beneficia uma parte ínfima da humanidade, tende a esgotar- esses combustíveis e não será possível repô-los. Além disso, seu consumo trouxe danos sérios à vida humana, como o efeito estufa formado pelas emissões de gases de efeito estufa e as mudanças climáticas daí decorrentes, com todas as suas consequências negativas que Jonas menciona: derretimento das calotas polares, elevação dos oceanos e inundações entre outras.

2) renováveis: energia hidrelétrica: seu potencial no Planeta não poderia substituir todos os usos dos combustíveis fósseis. O mesmo vale para a conversão da radiação solar em energia motriz térmica e elétrica. A energia eólica e das marés também poderiam suprir parte da energia hoje fornecida pelos combustíveis fósseis, mas nunca a sua totalidade.

3) nuclear: O uso da energia nuclear advinda da fissão nuclear é controversa não só pelos seus riscos, mas pela falta de opções seguras para seus rejeitos. Além disso, também o urânio pode se esgotar. A fusão nuclear controlada poderia fornecer uma fonte inesgotável de energia, caso ela fosse no futuro descoberta. Mas, mesmo assim, o problema térmico se apresenta ${ }^{10}$.

O problema térmico: todo o consumo de energia se dispersa em calor e por isso mesmo a fusão nuclear terminaria por aquecer o planeta igualmente, mais ainda se considerarmos que a utopia de uma sociedade de abundância implica uma sociedade com bilhões de pessoas com alto padrão de vida. Aqui se impõe, cita Jonas, a "inflexível lei da entropia, de acordo com a qual se "perde" energia toda vez que ela é consumida, toda energia degenera a fim em calor e o calor se dissipa, compondo com o ambiente ưm valor médio. Para a lei da termodinâmica, esses termos são inegociáveis". ${ }^{11}$

A conclusão de que existem limites naturais para enfrentar problemas tão essenciais quanto os referentes à produção de alimentos, à extração de matérias-primas e energia leva Jonas, então, à defesa da precaução. Seria necessário, portanto, uma ciência que fosse capaz de calcular esses limites, e além disso, "saiba lidar com a complexidade das interdependências", ou seja, uma nova ciência ${ }^{2}$. Assim, "enquanto não existirem projeções seguras - levando-se em conta, particularmente, a irreversibilidade de muitos processos em curso -, a prudência será a melhor parte da coragem e certamente um imperativo da responsabilidade; talvez para sempre, se, por exemplo, para avaliar o conjunto das nossas possibilidades técnicas, aquela ciência tiver que captar a totalidade dos dados para então processá-los em suas inter-relações. A incerteza poderá ser o nosso destino permanente - o que acarreta consequências morais."13

Até aqui Jonas. Mas antes de passar à discussão sobre como tal debate sobre os limites da Natureza seguiu adiante, valeria à pena observar como esse debate já se dava ainda no período em que Jonas escreveu.

\footnotetext{
8 Ibidem, p.302.

9 Ibidem, p.303.

10 Ibidem, 305.

${ }^{11}$ Tbidem, 306.

${ }^{12}$ Ibidem, 307.

${ }^{13}$ Ibidem, 307.
} 
Em 1972, a divulgação do Relatório "The Limits of the Growth"14, resultado de uma pesquisa encomendada pelo Clube de Roma a um conjunto de cientistas, e onde pela primeira vez se usou um programa computacional para estimar os limites de algumas variáveis como produção de alimentos, crescimento populacional, industrialização, poluiç̧ão e consumo de recursos naturais não renováveis, causara muito mal estar. Sua principal conclusão, expressa com todas as letras era que:

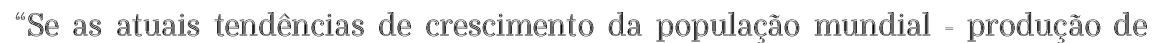
alimentos, industrialização, poluição e diminuição de recursos naturais não renováveis continuarem imutáveis -, os limites de crescimento nesse planeta serão alcançados algum dia, dentro dos próximos cem anos. O resultado mais provável é um declínio súbito e incontrolável, tanto da população, quanto da capacidade industrial" ${ }^{15}$

Ou, em outros termos, aquilo que na literatura ou no cinema de ficção científica podemos chamar de distopias. Para evitar esse futuro catastrófico, o Relatório propunha que se adotassem políticas visando o equilíbrio econômico e ecológico. Isso asseguraria a "satisfação das necessidades básicas" de todos os habitantes da Terra "até um futuro remoto". Em outras palavras, que parássemos de crescer.

Porém, não foram só os países "em desenvolvimento" que consideraram a proposta de uma parada nas curvas exponenciais de crescimento econômico como uma proposta que visava prejudicar "o seu desenvolvimento", agora que chegava a sua vez, mas também os países industrializados a rejeitaram, pois esse condenava seus altos níveis de consumo, considerados insustentáveis. O mundo socialista tampouco aceitou tal conclusão e a questão ambiental passará mais de uma década fora da agenda internacional até que a contradição que parecia insolúvel entre crescimento econômico e proteção do meio ambiente parecesse superada pelo novo conceito que surge com o Relatório Brundtland, "Nosso Futuro Comum", o conceito de Desenvolvimento Sustentável, em 1987. Como defende Marcos Nobre em "Desenvolvimento Sustentável: a institucionalização do conceito", ${ }^{16}$ tal conceito é deliberadamente vago e ambíguo, pois responde a uma estratégia de tornar palatável o debate ambiental ao defender, pela junção das duas palavras - desenvolvimento e sustentável - que pudesse haver a possibilidade de continuar crescendo economicamente e ao mesmo tempo, preservandose o meio ambiente.

Desde a formulação do conceito de desenvolvimento sustentável é que, efetivamente, a questão ambiental pode ser reintroduzida na agenda internacional e é logo em seguida que a Assembleia da ONU se decide por realizar uma nova grande conferência ambiental, a Eco-92, ou a Rio-92, vinte anos depois da Conferência de Estocolmo, sobre o "Meio Ambiente Humano", na qual o Relatório "Limits of the Growth" tinha sido apresentado e criticado. Assim, as diversas críticas que se possa fazer ao conceito do desenvolvimento sustentável, embora válidas, não deveriam desconhecer que essa sua vaguidão foi deliberada, pois foi ela que teria permitido reintroduzir a temática ambiental no âmbito das negociações ambientais.

Com isso quero dizer que quando Jonas lançou o Princípio Responsabilidade, e, 1979, seu posicionamento estava longe de corresponder a mainstream, pois esse havia relegado a fóruns técnicos a discussão sobre meio ambiente e ignorado a discussão, mais difícil, sobre os limites do crescimento. A descrição que Jonas fez, contudo, sobre os problemas referentes à alimentação, às matérias-primas e à energia, merece poucas correções e acréscimos a serem feitos tantos anos depois. Na questão agrícola, além de todos os impactos que ele descreveu - uso de fertilizantes, poluição de recursos hídricos

${ }^{14}$ MEADOWS, Dennis L., The Limits to Growth: a Report for the Club of Rom's Project on the Predicment of Mankind. Nova Iorque, Universe Books, 1972.

${ }^{15}$ Idem, p.23 [tradução minha].

${ }^{16}$ NOBRE, Marcos e Murício de Carvalho Amazonas (orgs.) Desenvolvimento Sustentável: a institucionalização de um conceito, Brasilia, Ed. IBAMA, 2002, Parte I pags.27 a 106. 
e áreas costeiras, salinização dos solos, erosão e desmatamento, caberia apenas acrescentar o envenenamento mundial com agrotóxicos e a erosão genética com a perda de variedades e espécies.

No problema das fontes energéticas, desenvolveram-se tecnologias para a extração de petróleo em camadas profundas - o pré-sal - e o gás de xisto, ambas com seríssimos impactos ambientais locais, o que somadas ao aumento da extração de petróleo em todo o mundo, barateou o preço do petróleo e estimulou o seu consumo mais ainda. Os impactos das mudanças climáticas, por outro lado, estão cada vez mais evidentes, desde eventos extremos como grandes secas com seus incêndios, inundações ou ondas de frio, até o desgelo da Groenlândia, proliferação de doenças tropicais e ressacas violentas ${ }^{17}$.

Por outro lado, cresceu bastante a produção de energia eólica, solar e das marés em todo mundo, particularmente em alguns países com os nórdicos, a Espanha, a Alemanha e mesmo a China. No entanto, os limites e as características dessas fontes energéticas impedem que elas possam suprir todos os atuais usos dos combustíveis fósseis. A energia hidroelétrica, além disso, já não pode mais ser considerada uma energia renovável, pois se a água dos rios é renovável - mantidas as condições de sua captação pelos solos - a destruição de ecossistemas, extinção de espécies a expulsão de populações nas áreas de suas represas e mesmo a possibilìdade de abalos geológicos não pode ser excluída ${ }^{18}$. Fora isso, descobriu-se que represas situadas em regiões com forte oscilação entre cheias e secas podem ser grandes geradoras de metano, o mais possante dos gases de efeito estufa.

Finalmente os senões apontados por Jonas em relação à energia nuclear permanecem inalterados, infelizmente comprovados pelo acidente nuclear de Chernobyl, em 1986 e em Fukushima, em 2011. Igualmente permanece insolúvel a questão da disposição final dos rejeitos atômicos, que são eles próprios agravantes nos acidentes nucleares e tampouco encontrou-se a solução milagrosa da fusão nuclear como fonte eterna de energia.

Na verdade, à menção às leis da termodinânimica como limites incontornáveis ao crescimento econômico, demonstra um grande acordo de Jonas com uma tese que sofrerá enorme rejeição por parte da teoria econômica neoclássica, a tese do matemático Georgescu-Roegen, A Lei da Entropia e o Problema Econômico, publicada também em 197919. Para Georgescu-Roegen, a economia neoclássica repousa sobre um dogma mecanicista, que lhes permite apresentar o processo econômico por meio de um diagrama circular em que a produção e o consumo ocorrem dentro de um sistema inteiramente fechado. Também a economia marxista considera que o que a Natureza oferece ao homem não tem valor, por ser gratuita. Como sabemos, só teria valor para essa teoria aqueles bens que seriam resultantes do trabalho abstrato socialmente necessário. O esquema de reprodução ampliado do processo econômico marxista também se apresenta, assim, como um conjunto absolutamente circular ${ }^{20}$.

Entretanto, argumenta Georgescu-Roegen, é evidente que há uma interação contínua entre o processo econômico e o meio ambiente material e toda a história da humanidade prova que a Natureza também tem um papel importante no processo econômico e na formação do valor. $\mathbb{E}$ estaria mais do que na hora de reconlhecê-lo, dadas as consequências que tal fato traz para a evolução da economia humana.

Assim, enquanto a primeira lei da termodinâmica estabelece que os seres humanos não são capazes de criar nem de destruir matéria ou energia, a segunda lei, também chamada de Lei da Entropia, postula que a energia térmica livre de um sistema

\footnotetext{
${ }^{17}$ International Panel for Climate Change (IPCC) 2019. hitps:/www.ipcc.ch/site/assets/uploads/2019/07/SPMPortuguese-version.pdf (último acesso).

${ }^{18}$ ZHOURI, Andréa(org.) As tensø̃es do lugar: hidroelétricas, sujeitos e licenciamento ambiental. Belo Horizonte, Editora UFMG, 2011.

${ }^{19}$ GEORGESCU-ROEGEN, Nicholas, O decrescimento: entropia.ecologia.economia. São Paulo, Senac, 2012, pags. 55 a 71.

${ }^{20}$ Idem, p.56. 
fechado se degrada contínua e irreversivelmente em energia presa, ou que a ordem de um sistema transformar-se continuamente em desordem. Ou, ainda em outras palavras e como a nossa experiência comprova, o calor passa sempre do corpo mais quente para o mais frio, e é impossível que um calor que tenha se difundido por um sistema a partir de um corpo mais quente possa retornar e concentrar-se novamente neste corpo sem uma intervenção externa. Daí, aquele amargo corolário da Física:

"A Lei da Entropia nos ensina que a regra da vida biológica, e no caso do homem, de sua continuação econômica, é muito mais severa. Em termos de entropia, o custo de todo empreendimento biológico ou econômico é sempre inaior do que o produto. Em termos de entropia, tais atividades se traduzem necessariamente por uim déficit".

Por isso, a ideia de um processo econômico como fenômeno isolado e circular, comum tanto à economia neoclássica quanto à economia marxista seria absolutamente falsa. "O processo econômico está solidamente apoiado numa base material que está sujeita a pressões bem precisas". 22 Por isso, ele evolui em um sentido único. Não reconhecê-lo, continua Georgescu-Röegen, como fazem os economistas, é ser vítima de um fetichismo da moeda, pois somente ela circula no mundo econômico em dois sentidos, ainda que até a moeda metálica se desgaste lentamente, tendo que ser substituída por novos depósitos minerais.

Ora, de onde viria a crença, então, de que a humanidade poderia continuar a crescer materialmente, independentemente desses limites físicos, se questiona Georgescu-Roegen? Provavelmente da Revolução Industrial, responde ele, na qual os grandes e notáveis avanços da técnica fizeram-nos crer que teríamos soluções técnicas e científicas para quaisquer desafios futuros, inclusive para o esgotamento de recursos. Seria preciso reconhecer, portanto, que a postura de ignorar os limites físicos do planeta é da ordem da crença, e não da ciência. O fato é que a humanidade encontrou modos de fugir ao reconhecimento dessa dura verdade e isso apareceu tanto no conceito de Desenvolvimento Sustentável, quanto mais tarde no de Economia Verde, que foi lançada com grande estardallhaço na Rio+20, em 2012.

Quais são as principais críticas, então, que podemos fazer ao conceito de Desenvolvimento Sustentável? Sumariamente, não se sabe exatamente o que se quis dizer com "desenvolvimento"23. O que é isso? Qual a sua relação com o crescimento econômico? Ainda que muitos defendam que a melhoria de qualidade de vida na saúde, na educação, na moradia sejam objetivos desejáveis e perseguíveis, todas as correntes econômicas relacionam a obtenção dessas melhorias a também um crescimento econômico, que permitiria distribuir esses bens e serviços aos mais desfavorecidos.

Destoam dessa concepção de "desenvolvimento" apenas aqueles partidários da crítica do Nobel de Economia, Amartya Sen ${ }^{24}$, que entende o conceito de "desenvolvimento" como a ampliação das nossas liberdades ou direitos: à saúde, à educação, à participação política nas sociedades e a tantos outros aspectos das nossas vidas que não podem ser reduzidos a valores monetários. A disponibilidade de renda suficiente para uma vida digna é um desses itens, mas por si só não garante os demais, nem traz consigo felicidade. Os índices de desenvolvimento humano que começaram a ser produzidos pela ONU, inspirados nesse conceito, tem o mérito de relativizar o peso da renda per capita, mas não são capazes de quantificar todos os aspectos responsáveis pelo nosso "desenvolvimento", até porque ieles não são plenamente quantificáveis e portanto não servem devidamente para comparações entre países ou dentro de países entre épocas diferentes.

\footnotetext{
${ }^{21}$ Idem, $\mathrm{p} .61$.

${ }^{22}$ Idem, p.63

${ }^{23}$ VEIGA, José Eli da, Desenvolvimento Sustentável: o desafio do século XXI. Rio de Janeiro, Gamond, 2005.

24 SEN, Anartya, Desenvolvimento como liberdade São Paulo, Companhia das Letras, 2004.
} 
Com o adjetivo "sustentável" que acompanha o substantivo "desenvolvimento", as dificuldades se renovam. Tanto podem ser entendidas como sustentáveis práticas como a reciclagem, mesmo que de substâncias perigosas, como a mera redução ou economia de recursos, ou seja, um conjunto de práticas em si elogiáveis e importantes de serem adotadas, chamadas de "produção mais limpa", ou ecoeficiência ou mesmo Produção Limpa, quanto propostas que proponham crescimento zero, de forma a reduzir ao máximo a perda de recursos. Pior ainda, o termo sustentável passou a ser usado em um sentido lato, para incluir não só práticas ecologicamente amigas, mas também para qualificar negócios que tenham boas perspectivas de continuidade e crescimento ${ }^{25}$.

$\mathrm{Na}$ verdade, há uma aposta implícita em que o uso de tecnologias mais avançadas permitirá a economia de recursos na produção de bens e a redução contínua de resíduos, permitindo assim um crescimento constante. Mas a miniaturização de produtos, com o emprego cada vez mais reduzido de matérias-primas e energia, não garantiu a redução do volume total de matérias-primas e energia consumidas. Ao contrário, permitiu sua expansão, graças ao chamado efeito de "rebote", ou bumerangue. Sobrando mais recursos, produz-se mais. Mas a crença nas possibilidades de compatibilizar crescimento econômico com proteção ao meio ambiente sobreviveu, mesmo com o razoável desgaste do termo desenvolvimento sustentável, e ressurgiu no conceito de Economia Verde, desenvolvido e apresentado durante a Rio+20, em 2012. Agora se trataria de favorecer o investimento público e privado em tecnologias que ao mesmo tempo que protegeriam o meio ambiente, trariam uma valorização dos investimentos feitos. Renova-se assim, a crença no poder miraculoso das tecnologias, mas dá-se maior ênfase às virtudes do mercado ao se transformar bens naturais em mercadoria e mercadorias em ativos da bolsa: créditos de carbono, Redução sobre Emissões de Desmatamento $\mathbb{E}$ vitado (REED) e outros títulos passíveis de serem criados e comercializados no mercado financeiro global26.

Se novas tecnologias não podiam ser a solução para o rápido esgotamento de recursos não renováveis e mesmo renováveis, muito menos o mercado o poderia ser, em especial o mercado financeiro, dada a sua natureza especulativa intrínseca e vulnerável às oscilações cíclicas de uma economia globalizada. Setores da esquerda convertidos à causa ambiental, por sua vez, tanto se satisfizeram com o conceito de desenvolvimento sustentável e de eficiência ecológica quanto aderiram ao conceito igualmente vago do ecossocialismo, no qual a vaguidão tanto está no termo eco, como no socialismo que é por ele qualificado.

Por fim, a Ecologia Política, que dá substrato aos movimentos de Justiça Ambiental, ao enfatizar a questão do acesso aos recursos e não o do seu uso e seus limites, também deixa de lado essa problemática hard, e mesmo em caso extremos, chega à refutá-la. Mas, o problema é que, sem enfrentá-la, não há verdadeiro enfrentamento da questão ambiental.

Para tal, no entanto, seria preciso rever o próprio ideal de sociedade da modernidade, que tanto na sua versão capitalista, como socialista, supôs um mundo de bens e serviços abundantes graças ao desenvolvimento da técnica, ou no vocabulário marxista, das forças produtivas. Afinal, são elas mesmas, a técnica e as forças produtivas, que nos levaram a essa crise ambiental, à qual podemos acrescer uma sociedade do desemprego, da exclusão e da desigualdade social27.

Todas as novas propostas políticas que surgiram de parte da sociedade civil, de movimentos e de organizações não-governamentais insistem na necessidade de abandonar o ideal do consumo crescente. O Bem Viver de nossos povos andinos defendem um ideal de felicidade atingido pela harmonia das relações dos seres humanos consigo mesmos, com os demais e com a Natureza. $\mathbb{E}$ também uma concepção biocêntrica

${ }^{25}$ VEIGA, José Eli da. Sustentabilidade, a legitimação de um novo valor. São Paulo, Senac, 2010.

${ }^{26}$ MORENO, Camila: "Las ropas verdes del rey: la economia verde: una nueva fuente de acumulación primitiva". In GRUPO PERMANENTE DE TRABAJO SOBRE ALTERNATIVAS AL DESARROLLO, Buenos Aires, América Libre, 2012

${ }^{27}$ BECK, Ulirich, Sociedade de Risco: rumo a uma outra modernidade, São Paulo, Editora $34,2010$. 
da Natureza: o Direito da Natureza ${ }^{28}$. E o Decrescimento propõe que nos livremos da ideia de que o crescimento da produção material seja algo bom e possível29. Como já se disse, quem acredita que é possível continuar sempre crescendo, ou é louco, ou economista. Ou ainda, na frase de Georgescu-Röegen, "um dia a humanidade terá que se encontrar com a Natureza".

Também em sua recente Encíclica, Laudato Si, o Papa Francisco pregou um modo de vida modesto, única forma de respeitar e proteger a Natureza que seria a nossa casa comum ${ }^{30}$.

Viver com menos e mesmo assim viver melhor nos remete por isso justamente aquela última parte do Princípio Responsabilidade de Hans Jonas, que comentei no início. Menos amada do que as demais partes de sua obra, aquele capítulo, entretanto, me parece justamente um dos mais importantes pois é nele, em contraposição à expectativa de criação de um homem novo que só seria possível quando as necessidades materiais humanas estivessem superadas, que Jonas advoga para que preservemos e amemos esse ser humanos que conhecemos ao longo da História, que apesar de suas vilezas e defeitos também foi capaz de grandezas e qualidades.

Essa insistência me parece muito importante, pois na busca socialista pela criação de um homem novo, há implicitamente uma rejeição de um homem velho, esse que teria existido até agora. Nesse sentido, o socialismo, embora se apresente como humanismo, parece rejeitar aquele que até hoje conhecemos como humano, já que fruto de sociedades injustas e desumanas.

Tal concepção não é correta, em primeiro lugar, porque não fomos e não somos cada um de nós, apenas produtos de sociedades injustas e limitadas, como tantas vezes nós, os cientistas sociais gostamos de dizer. Na arte, na ciência, na vida social e moral, muitas vezes transcendemos o nosso tempo e o nosso ambiente e a ele nos opomos, o criticamos e o transformamos. Além disso, as condições sociais, ou relações sociais que conhecemos na História não reuniram em si só iniquidades e obscurantismo, mas também avanços e luzes. Há ambivalências em todas elas e isso reconhecemos ao considerar a contribuição da democracia ateniense para o ideal democrático, o exemplo de solidariedade que emerge de sociedades mais igualitárias como as sociedades tribais, a importância das cidades como espaço de experiência política e cidadania e a valorização dos indivíduos no capitalismo, libertos dos vínculos de sujeição pessoal comuns às demais sociedades, como o próprio Marx o apontava. Da mesma forma, cada um de nós sempre desfrutou de uma liberdade interior que pode nos levar a assumir posturas inclusive contrárias à sociedade, à família e à nossa época e desenvolver ideias e percepções que a transcendem, razão pela qual até hoje lemos com prazer Aristóteles, São Tomás de Aquino, Shakespeare ou Dostoievsky e com eles aprendemos um pouco mais sobre nós.

Por isso, abandonar o projeto do progresso material infinito não deveria ser tão doloroso, pois o que efetivamente sempre valoramos na humanidade foram e são nossas relações sociais feitas de amor, de solidariedade e de generosidade. $\mathbb{E}$, se de fato queremos deixar a nossos filhos, netos e bisnetos um futuro agradável na Terra, é preciso que nos mobilizemos já para mudar nossa conduta e nossas expectativas do que seja uma boa vida de forma radica ${ }^{31}$. Acreditem, não será a última vez que a humanidade experimentará uma virada radical em seu modo de vida. O fim do Império Romano, a Reforma, o "Achamento" das Américas e a hecatombe que isso significou para

${ }^{28}$ ACOSTA, Alberto, O Bem Viver. uma oportunidade para imaginar outros mundos, São Paulo, Autonomia Literária/Elefante, 2016.

${ }^{29}$ LATOUCHE, Serge, Pequeno Tratado do Decrescimento Sereno, São Paulo, Martins Fontes, 2009

30 PAPA - TPANCTSCO,

Laudato

$S i_{9}^{\circ}$

https:/w2.vatican.va/content/dam/francesco/pdf/encyclicals/documents/papa-francesco_20150524_enciclicalaudato-si po.pdif

${ }^{31}$ CASTELLS, Manuel, Outra Economia é Possível: cultura e economia em tempos de crise, Rio de Janeiro, Zahar, 2019; WALLACE-WELLS, David, A Terra Inabitável: uma história do futuro, São Paulo, Companhia das Letras, 2019; RAWORTH, Kate, Economia Donut: uma altemativa ao crescimento a qualquer custo, Rio de Janeiro, Zahar, 2019. 
os povos originais das Américas, o advento do Capitalismo e a destruição das sociedades tradicionais, a Revolução Francesa, o Imperialismo europeu e a partillha do mundo no fim do século XIX, a Revolução Socialista e o fim do Império Russo, a Segunda Guerra Mundial e finalmente o fim do mundo soviético Foram todas viradas radicais e traumáticas. E a humanidade sobreviveu.

Mas essa virada radical é, agora, não só possível, mas indispensável. Sem ela, possivelmente não haverá mais história.

\section{Referências}

JONAS, Hans. O Princípio Responsabilidade: ensaio de uma ética para a civilização tecnológica, Rio de Janeiro, Contraponto/Editora PUCRio, 2006.

NOBRE, Marcos e Murício de Carvalho Amazonas (orgs.) Desenvolvimento Sustentável: a institucionalização de um conceito, Brasília, Ed. IBAMA, 2002.

GEORGESCU-ROEGEN, Nicholas, O decrescimento: entropia.ecologia.economia. São Paulo, Senac, 2012.

VEIGA, José Eli da, Desenvolvimento Sustentável: o desafio do século XXI. Rio de Janeiro, Garmond, 2005.

ACOSTA, Alberto, O Bem Viver: uma oportunidade para imaginar outros mundos, São Paulo, Autonomia Literária/Elefante, 2016.

LATOUCHE, Serge, Pequeno Tratado do Decrescimento Sereno, São Paulo, Martins Fontes,

2009.

Doutora em Ciências Sociais (PUC-SP)

Faculdade de Ciências Sociais (PUCSP)

E-mail: mlisboa@pucsp.br 